\title{
Analysis of the Plight and Countermeasures of Young Peasant Workers Returning Home to Start Business under the new normal
}

\author{
Jun Wang \\ General Education Center, Xijing University, Xi'an, Shaanxi 710123, China \\ wangjun2891@163.com
}

Keywords: New normal; young peasant workers; returning home to start a business; predicament; countermeasure.

\begin{abstract}
Young migrant workers as an important force for national innovation driven development, its return home, entrepreneurship, innovation, and effectively promoted the new rural construction, the construction of new urbanization and urban-rural integration development. Young migrant workers returning home to start a business has a positive social role, analysis of the unique individual characteristics of young migrant workers, explore the plight of its entrepreneurial innovation, put forward the countermeasures to perfect young peasant workers returning home to start an undertaking.
\end{abstract}

\section{Introduction}

Under the new normal, China is facing the "three phase superposition" challenges: growth rate into the shift, structural adjustment is facing labor pains, the early stimulus into the digestive period.At the same time, it is also faced with great opportunities for steady economic growth, more diversified growth momentum and more stable development prospects.Under the new normal, labor-intensive and extensive industries should be accelerated to intensive industries,low value-added labor intensive industries have been eliminated,migrant workers are seriously impacted by layoffs because they are at the very end of the industrial chain,forced back from the city to the countryside,formed a unique phenomenon of migrant workers returning home, and effectively promoted the entrepreneurial innovation of migrant workers returning home. [1]."Young migrant workers",different from the older generation of migrant workers,the age between 16 and 35 years old,born in 80s and 90s,the youth groups of migrant workers, who are in different places with non-agricultural employment as the main agricultural population.They grew up with the reform and opening up of the country, in the city gradually formed the values and behavior norms of young people in the new era.In the "Mass entrepreneurship and innovation" inspired by the strategic thinking of this era,along with the socialist new rural construction, new urbanization construction, and promote the integration of urban and rural development and other national guidelines and policies,a series of specific measures, such as strengthening agriculture, benefiting farmers, encouraging public innovation and entrepreneurship, strengthening the construction of urban and rural infrastructure, and promoting the construction of migrant workers' pioneer parks, have been introduced in succession,young migrant workers, as an important force in the development of national innovation, choose to return to the countryside and realize their self-worth,they are making progress and growing with the construction of new rural areas and urbanization in their hometown.As a unique group, the return of young peasant workers is also faced with many restrictive factors. Therefore, it is of great practical significance to study and perfect the guarantee mechanism for young peasant workers to return to their hometown and start their own businesses.

\section{Social Function of Young Peasant Workers Returning Home to Start an Undertaking}

\subsection{For New Urbanization and New Rural Construction to Inject New Vitality}

Young migrant workers return home to start their own businesses, so that the city's advanced 
technology and a large number of funds flowing to rural areas,the establishment of the agricultural industry and the enhancement of rural consumption ability have greatly helped the development of the rural economy, helped the villagers to become rich, and injected new blood and new vigor into the construction of the new countryside.[2]

\subsection{Promote the Transfer of Labor,Talent and Population, and Accelerate the Balanced Development of Urban and Rural Areas}

There are certain skills of migrant workers continue to join the city's construction, so that most of the stay in the rural areas are some old, weak, sick, disabled and pregnant groups.Young migrant workers return home to start business, they solved the problem of talents in rural development, and at the same time led to more rural labor employment,for the transfer of rural labor to provide a new path, and fundamentally ease the pressure on urban employment.And then to narrow the gap between urban and rural areas, to promote the balanced development of urban and rural areas.

\subsection{Boosting the Development of Agricultural Modernization and Optimizing the Industrial Structure of Rural Economy}

It is an important practical way to realize the transfer of economic industry and structural adjustment for young peasant workers to return to their hometown and start their own businesses,return home business is more for agriculture, rural areas, farmers services.After the return of young migrant workers, through the development of large-scale agricultural management, the transfer of land, the creation of rural cooperatives, to speed up the development of modern agriculture.

\subsection{Participate in Rural Governance, and Maintain the Harmony and Stability of Rural Society}

Young migrant workers mostly work in cities such as the east and the coast for a long time,they are influenced by the culture of urban citizens and are likely to pursuit of more involved in hometowns construction rights,they also affect relatives and friends and the rural masses, so that villagers can pay more attention to rural development and participate in the development of rural areas. Young migrant workers spread modern urban governance thinking and ideas, and gradually grew into the main body of rural governance,change the way of rural governance, make the development of rural areas closer to the needs of the villagers, better serve the villagers, rural affairs are more transparent, and promote the harmonious and stable rural society.

\section{Individual Characteristics of Young Migrant Workers}

\subsection{Focus on Personal Development}

Compared to the older generation of migrant workers will earn money to support the family as the first requirement of migrant workers, young migrant workers have begun to pay more attention to personal development,pay attention to spiritual and cultural pursuit, the pursuit of personal rights and security aspirations more strongly.Has been dissatisfied with the economic income to return home to take a wife to live, migrant workers are mainly to pursue a better life and find opportunities for development, better broaden their horizons, learn to accumulate skills and experience.

\subsection{Entrepreneurial Aspirations are Strong}

Young migrant workers are young people with the spirit of adventure, willing to pursue new things and accept new challenges.Young migrant workers choose to go to Beijing, Shanghai, Guangzhou, eastern, coastal and other economically developed or more developed cities, many people in the work has been carries the dream of entrepreneurship, influenced by the high degree of modernization in coastal areas of culture, economy and thought,especially the influence of the concept of independent innovation, and thus more eager to achieve self, the desire of entrepreneurship is very strong. 


\subsection{Market Thinking is more Acute}

Young migrant workers work in the more developed regions, they contact completely different market economy environment which compare with the older generation, has a more profound understanding of the role of the market, more familiar with the market of production, supply and marketing system, some jobs of the sale,it is familiar with the market,have a keen awareness of the market and a broader economic view.

\subsection{Have some Elements of Human Capital}

Young migrant workers have received high school, tertiary education, they have a certain level of cultural knowledge, in the eastern coastal developed areas to accept the job skills training, contact with some advanced science and technology, to understand the modern mode of production and modern management, accumulated technology and experience, their ability to have a certain level of improvement, with a certain amount of human capital elements.At the same time, young workers choose to engage in a variety of industries, in the constant pursuit and frequent work replacement, and accumulated more market information and human resources.Compared with college students entrepreneurial groups, young migrant workers more skills reserves, more social experience, the requirements of the entrepreneurial threshold is even lower.

\subsection{Have the Fine Quality of Hard-Working}

Young migrant workers from childhood live in the countryside of the hard environment,still retain the peasant family-specific hard-working quality,for the difficult conditions of migrant workers,but also more experience,cultivate them certain independence and strong adaptability,to face the setbacks, the physical and mental endurance of overcoming suffering is stronger,compared to young people who graduated from school,these are the great advantages of young migrant workers returning home to start their own businesses,can help them successfully through the difficult period of entrepreneurship smoothly.

\section{The Dilemma of Young Peasant Workers' Entrepreneurship}

\subsection{Entrepreneurship Financing Difficult}

Young migrant workers go out to work for many years,accumulated some venture capital.However, as a venture capital,the accumulation of funds is often only enough for start-up funds,in the early days of entrepreneurship has been exhausted, so the continued investment in business and daily operation of enterprises is stretched.At the same time,many young migrant workers have reached the age of marriage,the accumulation of funds, but also need to be used for marriage,buy a house.At present, migrant workers entrepreneurship exists preferential policies of government financial support is not enough,the coverage is small;the rural financial service system is not perfect, functional deficiencies;rural financial credit product shortage,financing level is low and other issues to be solved. [3]Financing difficulties,limited channels,leading to follow-up entrepreneurial funds difficult to implement, so that the development of the project constraints.

\subsection{The Ability of Entrepreneurship Risk Control is Weak}

Young migrant workers,for the choice of venture projects,in the end how much risk,often in the heart have no idea.In the early stage of entrepreneurship,often not carried out a rigorous market research and analysis,and more experience and market feeling are adopted to select the venture industry and projects.Some of the choice of industry engaged in too many people,and even vicious competition,and some projects have been eliminated market,or at the end of the industrial chain.In the process of starting an undertaking,the understanding of the development of the industry is not comprehensive,the orientation of the long-term development is not clear,and the market trend can not be well grasped. 


\subsection{Lack of Entrepreneurial Technical Support and Management Knowledge}

Although young migrant workers have a strong learning ability and adaptability,but also after years of tempering,they have accumulated a certain industry experience and skills.However,the young peasant workers founded the enterprise technical content of most of the lower starting point, at the same time,individuals have not received the knowledge of system skills,the lack of advanced management knowledge,organizational culture level is low,Lack of entrepreneurial stamina.[4]

\section{Countermeasures of Young Peasant Workers Returning Home to Start a Business}

\subsection{Optimize Financing Channels and Reduce Start-up Costs}

The problem of financing for young peasant workers is gradually changing, and the country is giving financial support, tax relief, venture guarantee loans and other aspects of support.Local governments should also speed up the policy support of young migrant workers returning home for entrepreneurship,a series of measures and effective methods will be introduced as soon as possible,provide a variety of banking services model,the development of small and micro financial institutions,the establishment of venture capital, the introduction of private capital,at the same time optimize the loan approval process, arrange loans to subsidize funds, and create a good financial services environment.To further improve the infrastructure and other entrepreneurial environment, including transportation, logistics, network communications, rural water, electricity and sanitation and other infrastructure and related facilities to enhance the entrepreneurial service capacity and acceptance.Through the current promotion of "one address, multiple licenses" and other work, reducing the cost of young migrant workers returning home to start business.

\subsection{Provide Project Advice and Strengthen Vocational Skills Training}

The choice of entrepreneurial projects in the process of entrepreneurship has an important role, because the poor choice of entrepreneurial projects, in the entrepreneurial failure accounted for a large proportion.Mainly due to lack of market research assessment,blindly choose entrepreneurial projects. The Government in this regard should provide some entrepreneurial consulting training, young migrant workers to select the venture project evaluation consulting,to control the risk of entrepreneurship,guide young peasant workers to select some national policies and encourage projects,such as leisure agriculture,forest economy and rural tourism,to promote the integration and development of the one or two and three industries in rural areas,adapt to the local environmental conditions, and their own professional skills closely,the capital investment is small,quick investment, income is guaranteed,and can be flexible according to their own conditions to control the scale of investment.Play the guiding role of the government and related institutions,aiming at the characteristics of the young migrant workers who return to work in the whole and engaged in various industries,designed to meet the market demand for education and training content,create reasonable forms of education and training, such as integrating existing resources of various vocational schools[5],set up specialized vocational training base for Chinese migrant workers, gradually form large-scale vocational education for migrant workers, and improve the quality of vocational training. This type of vocational training mainly for low academic,heavy career development of the new generation of young migrant workers groups,teaching methods short,flat, fast,suitable for returning youth entrepreneurship time and funding needs;construct an effective education and training network to facilitate the return of migrant workers,and more convenient access to educational and training resources and other types of information. The government should increase the efforts to raise funds for the education and training of young migrant workers, and earnestly invest and accumulate the human capital of young migrant workers,to provide reasonable supporting services, which include according to market demand, to seize the hot professional,timely adjustment of training content,the establishment of migrant workers return home information network,reasonably guide and develop the advantages and special skills of migrant workers returning home to start their own businesses,so as to enhance their competitiveness. 


\subsection{Guide Entrepreneurial Behavior and Create a Good Entrepreneurial Atmosphere}

All walks of life,especially the news media,should vigorously publicize the return of young migrant workers to start their own businesses,and play a role model demonstration by reporting some advanced models,guide a certain entrepreneurial potential of young migrant workers back to business,thus forming a good entrepreneurial cultural atmosphere.[6]The positive impact on young migrant workers is beneficial for young migrant workers to withstand the pressure caused by the external environment of entrepreneurship,to enable young migrant workers to find more sense of belonging and honor in entrepreneurship,enhance the recognition of the value of entrepreneurship, forming a willingness to start a business,dare to start a business, able to start a business,and willing to start a good atmosphere.

\subsection{Strengthen the Protection of Entrepreneurship System}

Young migrant workers return home to start their businesses as an economic and social activity,should be protected and bound by laws and regulations.Especially migrant workers youth groups,relatively unfamiliar with the laws and regulations,along with the development of enterprises,some products,patents and other disputes have become an obstacle to the rise of enterprises uncertain factors.At the same time,a good system can even prevent young migrant workers from being eager for success,such as tax evasion and other illegal activities.Professional laws and regulations can also protect the financial security of young migrant workers' start-up financing,avoid misappropriation and seizure,and protect the reasonable demands and legitimate rights and interests of young migrant workers.

\subsection{Construction of Migrant Workers to Return Home Electronic Business Platform}

Encourage e-commerce to penetrate into the rural areas of the West and the central part of the country and serve rural entrepreneurs. The current domestic rural entrepreneurs are doing almost all in the coastal developed areas,the vast majority of the central and western regions are relatively backward,in these areas is the main battlefield of migrant workers return home business.E-commerce platform can reduce the promotion costs, focus on the introduction of related brands,help migrant workers in these areas entrepreneurship.The development of migrant workers can not be separated from the improvement of the entrepreneurial environment by the grass-roots government,it provides convenience for migrant workers from infrastructure,preferential policies,entrepreneurship training and other aspects, the grass roots government should cooperate with the strategy of going to the countryside by e-commerce,complementary advantages,to maximize the mobilization of the parties involved in the enthusiasm and creativity,cooperate with e-commerce platform to improve and optimize the service for migrant workers.

\section{Conclusion}

Youth migrant workers return to their hometown to start a business as an important part of the national innovation-driven,innovative development strategy,should be in the transformation of agricultural development,promote the agricultural supply side of the structural reform,promote the optimization and upgrading of agricultural industry structure,to achieve agricultural modernization efforts to practice.Government society should pay attention to cultivate young migrant workers entrepreneurial innovation awareness,stimulate the passion of entrepreneurship,pay attention to strengthen the support and protection of young migrant workers entrepreneurship,and guide the establishment of the correct criteria for the evaluation of entrepreneurial value,advocating the pioneering spirit of being a pioneer,cultivate entrepreneurial tolerance of tolerant fail,guide the value orientation of advocating innovation and common prosperity.

\section{References}

[1] Qin long.Research on Entrepreneurial Strategies of migrant workers returning home from the perspective of New Countryside[J]. Continuing Education Research.2016 (07): 36. 
[2] Wang huan.Research on migrant workers returning home to start a business[J].Agricultural Economy.2009(09):66.

[3] Liu Yihai, Wang Lin.Research on financial support model of migrant workers returning home to start business[J].Journal of Henan University of Science and Technology. 2017(02):83.

[4] Wang xi.Research on Entrepreneurship of young migrant workers returning home in Jilin[J].Modern communication.2014(10):02.

[5] Yu Yunbo, Yu Lin.New urbanization process, new generation of migrant workers, vocational training, quality improvement strategy[J]. Adult Education.2017(01):53.

[6] Sun Xiaojie .Study on migrant workers returning home in Hebei Province[J].China Agricultural Information.2016(12):43. 